\title{
Realization of an Asynchronous Six-Phase Induction Motor Drive Test-Rig
}

\author{
R. Gregor ${ }^{1}$, F. Barrero ${ }^{1}$, S. Toral ${ }^{1}$ and M.J. Durán ${ }^{2}$ \\ ${ }^{1}$ Electronic Engineering Departments \\ E.S.I., University of Seville \\ Camino de los Descubrimientos s/n, 41092 Sevilla (Spain) \\ Phone/Fax number:+0034 954481293, e-mails: rgregor@esi.us.es, fbarrero@esi.us.es, toral@esi.us.es \\ 2 Electrical Engineering Department \\ E.S.I.I., University of Malaga \\ Pza.del Ejido s/n, 29120 Malaga (Spain) \\ Phone/Fax number:+0034 952132707, e-mail: mjduran@uma.es
}

\begin{abstract}
The potential advantages of multi-phase solutions over the conventional 3-phase ones have been widely discussed in the literature. Their feasibilities and performances have been recently described and proven. The main goal of this paper is to design and implement a test rig to evaluate control policies for a double-3-phase induction motor drive, a multiphase drive with an increasing interest in ship propulsion, locomotive traction or electrical vehicles (EV) applications.
\end{abstract}

\section{Keywords}

Multi-phase systems, modelling and simulation of electrical machines, experimental test-rig.

\section{Introduction}

Multi-phase motor drives have been studied from more than thirty years. Since the last two years, the interest has grown so that some international power electronic conferences have hosted sessions on the multi-phase motor drives [1]. Multiphase motor drives have been proposed for different applications where some specific advantages (lower torque pulsations, less DC link current harmonics, higher overall system reliability, better power distribution per phase) can be better exploited, justifying the higher complexity in contrast to the three-phase solution [2]. Some of the most suitable applications are the high current ones (ship propulsion, locomotive traction, electrical vehicles), where the main advantage of multi-phase drives consists of splitting the controlled current on more inverter legs, reducing the single switch current stress compared to the three-phase converters. Since the power switches rated current is reduced proportionally with the number of phases, an increment in the number of power switches does not represent an additional cost. On the contrary, the cost is reduced by the "non-linearity" of the component prices. However, the system cost is penalized by the increased number of the current sensors, gate drive circuits, additional circuitry power supply, etc., while the system complexity is also increased by the new difficulties with the applied control techniques.

Among the different multi-phase induction drives solutions, the dual-3-phase induction machine having two stator winding sets spatially shifted by 30 electrical degrees with separated neutral points has important advantages in applications like EV [3]-[4], where the low available DC-link voltage imposes high phase current. These electrical machines are convenient in high power and high current applications offering an interesting alternative to the conventional 3-phase counterpart. The current stress of each semiconductor power device is reduced by one half compared with the 3-phase machine counterpart, while the dual-3-phase solution can benefit of the wide availability of components dedicated to 3phase systems.

This work is going to cover the implementation of a testrig to analyze this kind of multi-phase drives. The detailed goal of the work is to design and develop a test rig for dual-3-phase induction motor drives, extending the traditional vector control techniques to these drives and solving specific problems like system asymmetries and high sensitivity to the dead-time effects or the onstage voltage drops, especially critical in application with a low voltage value involved in the drive operation.

An important operative result is the availability of a flexible and fast development tool to test future improvements, such as sensor number reduction, sensor less applications, and advanced control implementation for this kind of motor drives.

The paper is organized as follows. First, dual 3-phase induction motor drives and their applications are analyzed in section I. Next, section II describes the machine model including some simulations for better understanding. Section III presents the implementation of the novel test-rig. Finally, some conclusions are drawn in section IV. 


\section{Dual 3-phase Induction Motor Drives}

Conventional 3-phase drives have been extensively used in industry applications. However, if one of the phases is lost, the rotatory field also disappears and the machine stops. The multi-phase drives offer the improvement of the system reliability, which is of great interest in specialized applications such as electric/hybrid vehicles or aerospace applications. Independently of the number of phases the multi-phase machine has, it only needs two degrees of freedom to generate a rotatory field. Consequently, if one phase is lost the drive continues operating although at different rating values.

Because of this reason, during the last three decades there is a growing interest to research several issues related to the use of multi-phase drives as a potential alternative for the conventional three-phase systems. This is especially true for dual three phase induction motor drives and their applications [4]. This induction machine has two sets of three-phase windings which are spatially phase shifted by 30 electrical degrees with isolated neutrals, as shown in Fig. 1.

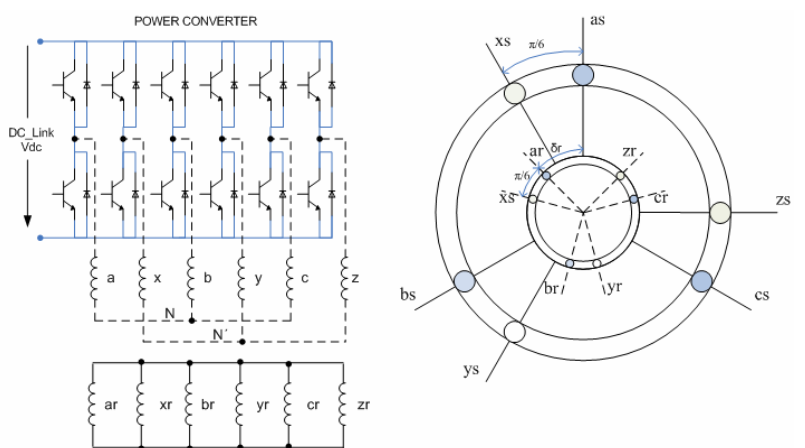

Fig. 1. Dual three-phase induction motor drive.

The dual three-phase induction machine is a six dimensional system. Therefore, modeling and control of this machine in the original reference frame would be very difficult. For this reason, it is necessary to obtain a simplified model to control it. To derive this model, some assumptions must be made like the sinusoidal distribution of the stator and rotor windings. Moreover, the magnetic saturation, the mutual leakage inductances and the core losses must be neglected. If so, the voltage equations in the original phase coordinates can be expressed as [6]:

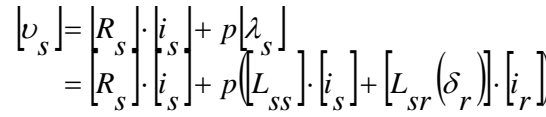

$$
\begin{aligned}
& \begin{aligned}
{[0] } & =\left[\begin{array}{l}
R_{r} \\
\end{array}\right] \cdot\left[\begin{array}{l}
i_{r} \\
R_{r}
\end{array}\right] \cdot\left[\begin{array}{l}
\left.+\lambda_{r}\right\rfloor \\
i_{r}
\end{array}\right]+p\left(\left[L_{r r}\right] \cdot\left[i_{r}\right]+\left[L_{r s}\left(\delta_{r}\right)\right] \cdot\left[i_{s}\right]\right)
\end{aligned}
\end{aligned}
$$

Where $\vartheta$ is the rotor angular position and $p=d / d t$ [5].

For analysis and control purposes, the original sixdimensional machine system can be decomposed into three two-dimensional orthogonal subspaces $(\alpha, \beta),\left(\mu_{1}\right.$, $\left.\mu_{2}\right)$ and $\left(z_{1}, z_{2}\right)$ by using the transformation matrix $T_{6}$ [7].

$$
T_{6}=k\left[\begin{array}{cccccc}
1 & -\frac{1}{2} & -\frac{1}{2} & \frac{\sqrt{3}}{2} & -\frac{\sqrt{3}}{2} & 0 \\
0 & \frac{\sqrt{3}}{2} & -\frac{\sqrt{3}}{2} & \frac{1}{2} & \frac{1}{2} & -1 \\
1 & -\frac{1}{2} & -\frac{1}{2} & -\frac{\sqrt{3}}{2} & \frac{\sqrt{3}}{2} & 0 \\
0 & -\frac{\sqrt{3}}{2} & \frac{\sqrt{3}}{2} & \frac{1}{2} & \frac{1}{2} & -1 \\
1 & 1 & 1 & 0 & 0 & 0 \\
0 & 0 & 0 & 1 & 1 & 1
\end{array}\right], \mathrm{k}=\frac{1}{3}
$$

Thus, applying the matrix (3) to the voltage equations (1), (2) yields:

$$
\begin{aligned}
{\left[\mathrm{T}_{6}\right]\left[\nu_{s}\right]=\left[\mathrm{T}_{6}\right] \cdot\left[\mathrm{R}_{s}\right] \cdot\left[\mathrm{T}_{6}^{-1}\right] \cdot\left[\mathrm{T}_{6}\right] \cdot\left[i_{s}\right] } \\
+p \cdot\left[[ \mathrm { T } _ { 6 } ] \cdot [ L _ { s s } ] \cdot [ \mathrm { T } _ { 6 } ^ { - 1 } ] \cdot [ \mathrm { T } _ { 6 } ] \cdot \left[\left[_{s}\right]\right.\right. \\
+\left[\mathrm{T}_{6}\right] \cdot\left[L_{s r}\right] \cdot\left[\mathrm{T}_{6}^{-1}\right] \cdot\left[\mathrm{T}_{6}\right] \cdot\left[i_{r}\right] \\
{[0]=\left[\mathrm{T}_{6}\right] \cdot\left[\mathrm{R}_{s}\right] \cdot\left[\mathrm{T}_{6}^{-1}\right] \cdot\left[\mathrm{T}_{6}\right] \cdot\left[i_{r}\right] } \\
+p \cdot\left[\mathrm{T}_{6}\right] \cdot\left[L_{r r}\right] \cdot\left[\mathrm{T}_{6}^{-1}\right] \cdot\left[\mathrm{T}_{6} 6\right] \cdot\left[i_{r}\right] \\
+\left[\mathrm{T}_{6}\right] \cdot\left[L_{r s}\right] \cdot\left[\mathrm{T}_{6}^{-1}\right] \cdot\left[\mathrm{T}_{6}\right] \cdot\left[\mathrm{i}_{s}\right]
\end{aligned}
$$

As shown in [6]-[7], the machine model can be divided into three sets of decoupled equations, corresponding to the three subspaces $(\alpha, \beta),\left(\mu_{1}, \mu_{2}\right)$ and $\left(z_{1}, z_{2}\right)$.

$$
\begin{aligned}
& {\left[\begin{array}{l}
v_{s \alpha} \\
v_{s \beta} \\
0 \\
0
\end{array}\right] } {\left[\begin{array}{cccc}
R_{s}+L_{s} \cdot p & 0 & M \cdot p & 0 \\
0 & R_{s}+L_{s} \cdot p & 0 & M \cdot p \\
M \cdot p & \omega_{r} \cdot M & R_{r}+L_{r} \cdot p & \omega_{r} \cdot L_{r} \\
-\omega_{r} \cdot M & M \cdot p & -\omega_{r} \cdot L_{r} & R_{r}+L_{r} \cdot p
\end{array}\right] } \\
& \cdot\left[\left[\begin{array}{llll}
i_{s \alpha} & i_{s \beta} & i_{r \alpha} & i_{r \beta}
\end{array}\right]^{t}\right.
\end{aligned}
$$

The $(\alpha, \beta)$ machine model is similar to the three-phase machine model in the stationary reference frame. Thus, equation (6) can be rewritten using the space vectors mapped in the $(\alpha, \beta)$ subspace:

$$
\begin{aligned}
\bar{v}_{s} & =R_{s} \cdot \bar{i}_{s}+p \cdot \bar{\lambda}_{s} \\
0 & =R_{r} \cdot \bar{i}_{r}+p \cdot \bar{\lambda}_{r}-j \cdot \omega_{r} \cdot \bar{\lambda}_{r}
\end{aligned}
$$

Where the flux linkage vectors are expressed as:

$$
\begin{aligned}
& \bar{\lambda}_{s}=L_{s} \cdot \bar{i}_{s}+M \cdot \bar{i}_{r} \\
& \bar{\lambda}_{s}=L_{r} \cdot \overline{i_{r}}+M \cdot \bar{i}_{s}
\end{aligned}
$$

The machine model in $\left(\mu_{1}, \mu_{2}\right)$ subspace can be expressed by equations (9), and in $\left(z_{1}, z_{2}\right)$ subspace by equations (10). 


$$
\begin{aligned}
& {\left[\begin{array}{l}
v_{s \mu 1} \\
v_{s \mu 2}
\end{array}\right]=\left[\begin{array}{cc}
R_{s}+L_{l s} \cdot p & 0 \\
0 & R_{s}+L_{l s} \cdot p
\end{array}\right] \cdot\left[\begin{array}{l}
i_{s \mu 1} \\
i_{s \mu 2}
\end{array}\right]} \\
& {\left[\begin{array}{l}
0 \\
0
\end{array}\right]=\left[\begin{array}{cc}
R_{r}+L_{l r} \cdot p & 0 \\
0 & R_{r}+L_{l r} \cdot p
\end{array}\right] \cdot\left[\begin{array}{l}
i_{r \mu 1} \\
i_{r \mu 2}
\end{array}\right]} \\
& {\left[\begin{array}{c}
v_{\mathrm{sz} 1} \\
v_{\mathrm{sz} 2}
\end{array}\right]=\left[\begin{array}{cc}
R_{s}+L_{l s} \cdot p & 0 \\
0 & R_{s}+L_{l s} \cdot p
\end{array}\right] \cdot\left[\begin{array}{l}
i_{s z 1} \\
i_{s z 2}
\end{array}\right]} \\
& {\left[\begin{array}{l}
0 \\
0
\end{array}\right]=\left[\begin{array}{cc}
R_{r}+L_{l r} \cdot p & 0 \\
0 & R_{r}+L_{l r} \cdot p
\end{array}\right] \cdot\left[\begin{array}{l}
i_{r 21} \\
i_{r z 2}
\end{array}\right]}
\end{aligned}
$$

The following can be noted:

1) The electromechanical energy conversion variables are mapped in the $(\alpha, \beta)$ subspace, while the nonelectromechanical energy conversion variables can be found in the two other subspaces.

2) The current components in the $\left(\mu_{1}, \mu_{2}\right)$ and $\left(z_{1}, z_{2}\right)$ subspaces do not contribute to the air-gap flux and are limited only by the stator resistance and stator leakage inductance, which is usually small. These currents will only produce losses and consequently should be controlled to be as small as possible.

3) The control of the dual three-phase machine is greatly simplified since it can be solved with the equivalent circuit in the $(\alpha, \beta)$ subspace, being similar to the equivalent circuit of a three-phase machine.

Using the proposed model, a Matlab/Simulink simulation environment has been designed for the dual 3-phase induction machine. Fig. 2 shows the simulation environment.

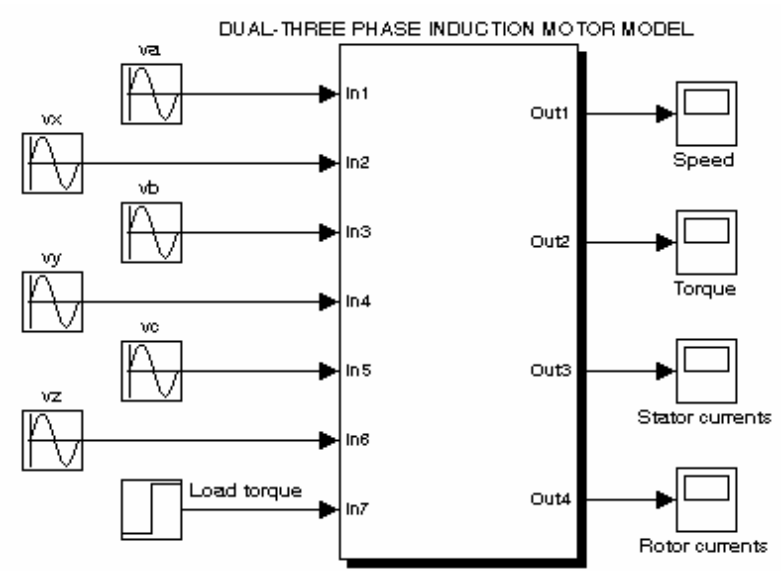

Fig. 2. Matlab/Simulink dual 3-phase induction machine simulation environment.

Some simulations have been done to prove the effectiveness of the proposed model. Fig. 3 shows the electrical torque evolution after applying sinusoidal stator voltages. A typical oscillation appears in the electrical torque produced by the dual 3-phase induction machine at the start-up process. This decaying variation in the instantaneous torque is due to the transient offset in the stator currents [8]. After one seconds, a load torque is applied to appreciate the dynamic response of the system.
Fig. 4 also depicts the speed decrement, after applying the load torque.

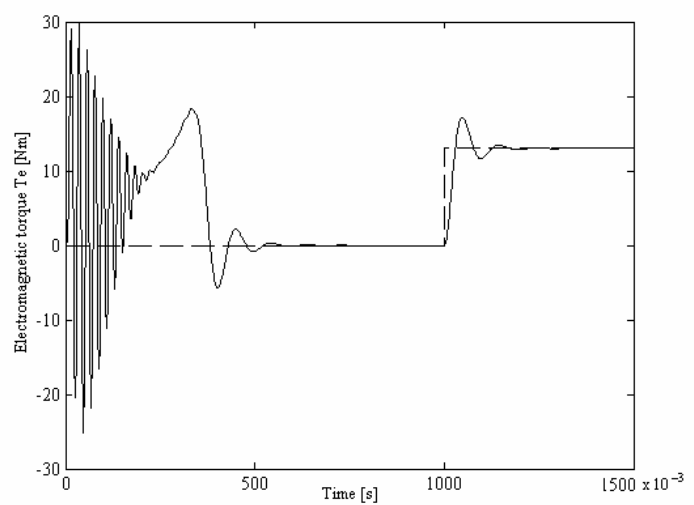

Fig. 3. Electrical torque evolution in a dual 3-phase induction machine using sinusoidal voltage supply.

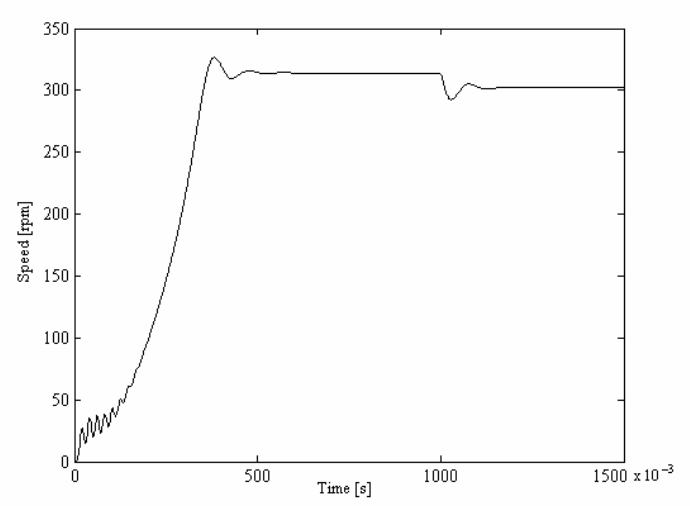

Fig. 4. Speed evolution during the simulation after starup period.

\section{Experimental Test-Rig}

An experimental test rig has been designed for implementing real applications based on these electrical machines. A diagram and photography of the complete system are shown in Figs. 5 and 6, respectively.

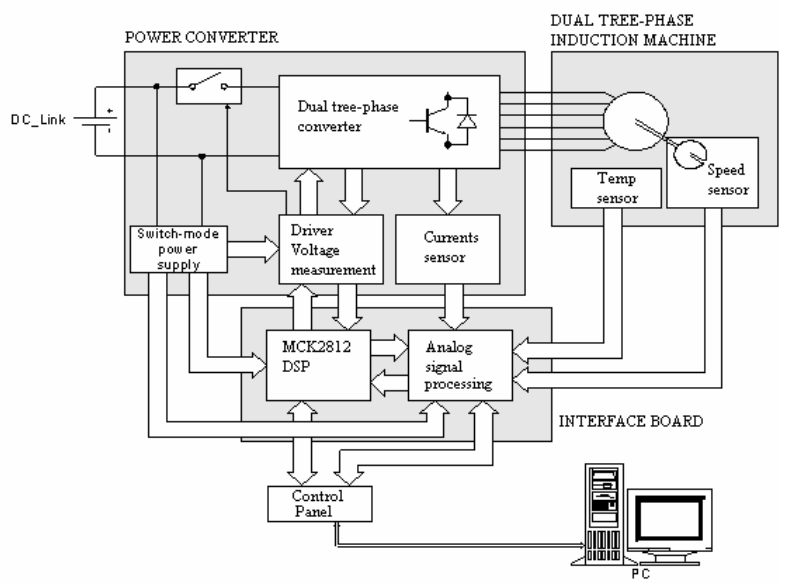

Fig. 5. Scheme of the implemented experimental test-rig.

The test-rig is based on a conventional 36 slots, 2 pairs of poles, $10 \mathrm{~kW} 3$-phase induction machine whose stator has been rewound to construct a 36 slots, 3 pairs of poles, dual 3-phase induction machine. Two sets of stator three- 
phase windings spatially shifted by 30 electrical degrees have been included, Fig. 7.

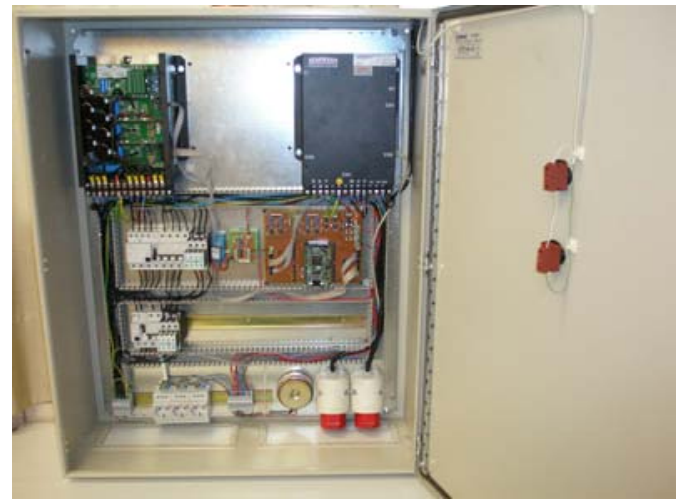

Fig. 6. A picture of the system, including the power and control modules.

Two Semistack-IGBT modules from Semikron Inc. (serie SKS21F) have been used to drive the machine, Fig. 8. Each module includes a pre charge circuit, handles up to 21 amperes, and allows a maximum switching frequency of $15 \mathrm{kHz}$ [9].

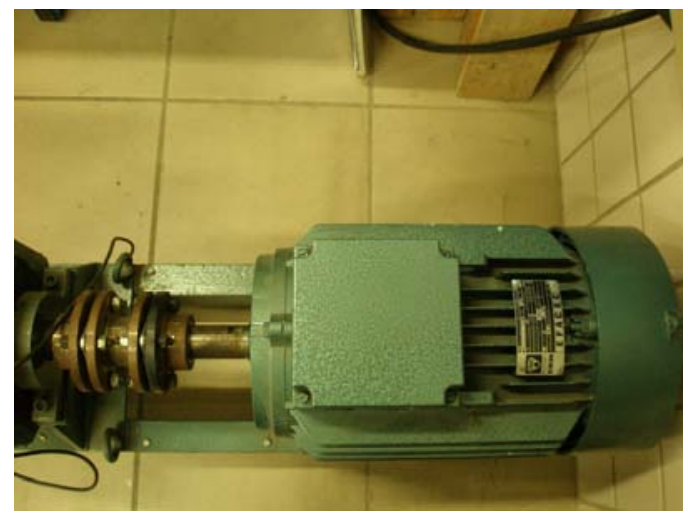

Fig. 7. Dual 3-phase induction machine.

Speed is also measured using a two channel, 10000 pulses per revolution, incremental encoder (serie GHM5_S6).

Moreover, an interface and a control boards have been designed and implemented to control the real system. The interface board is used to adapt analog signals providing from the current sensors (two LEM 55-P Hall-effect current sensors included in each Semistack to measure two phase currents, four current sensors for control purposes), and the DC-link voltage. The encoder and power switches control signals are also optocoupled in this board, which includes a conventional protection circuit designed to maintain system integrity against fault conditions.

The control board is based on a TMS320LF2812 Texas Instruments digital signal processor (DSP) and the MCK2812 system [10]. A diagram of the complete control board is shown in Fig. 9. This DSP provides peripheral for real time control of power systems. For instance, it includes up to twelve PWM outputs that be used to control two independent 3-phase voltage source inverters (VSI), including programmable dead time control systems. A peripheral for processing signals coming from a quadrature encoder in order to help the user to obtain the mechanical speed, and a highperformance 16 channels, 12-bits each one, analog- todigital converter with up to 12.5 MSPS of conversion rate are also provided.

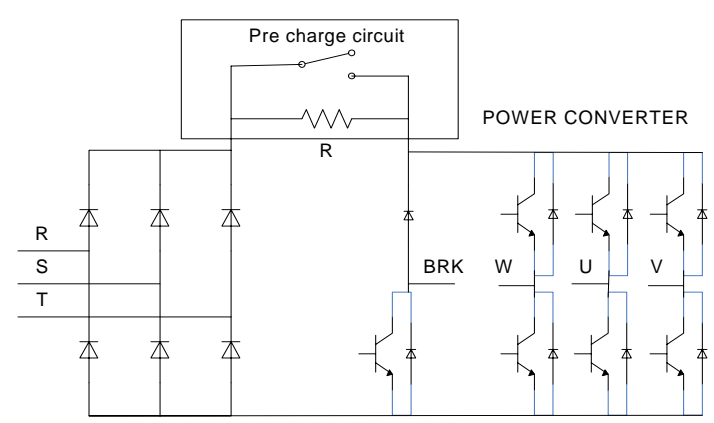

Fig. 8. Semistack-IGBT modules from Semicron Inc. (serie SKS21F).

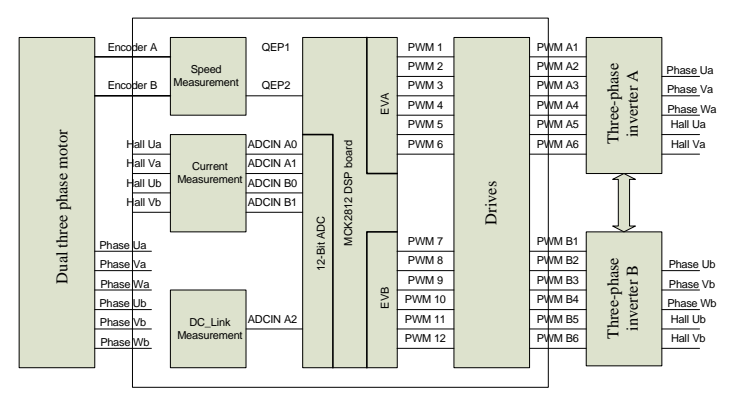

Fig. 9. Diagram of the complete control board (input and output).

\section{Conclusion}

The potential advantages of multi-phase solutions over the conventional 3-phase ones make this kind of electrical machines especially interesting in applications where a reduction of the rotor harmonic losses, the power semiconductor stress, the torque pulsation; or the harmonic content of the DC-link current (or the improvements of the overall system reliability) is imperative. Although these electrical machines are not new at all, they have only considered like an alternative to conventional 3-phase ones from the last few years. Consequently, the advantages or disadvantages of these machines have not completely tested, and their application areas have not been clarified. This paper presents the implementation of a testing environment for one of the most promising multi-phase solutions, the double 3-phase induction machine, as a first stage for proving the benefits of using this technology. In a second stage, more experimental results must be obtained to compare multi-phase against conventional electrical machines, and clarify, comparing their electrical behavior, their applications areas.

\section{Acknowledgement}

The authors gratefully acknowledge the Spanish Government for the financial support provided within the 
National Research, Development and Innovation Plan, under reference DPI2005/04438.

\section{References}

[1] E. Levi, "Editorial - Special Issue on Multi-Phase Motor Drives”, EPE Journal, Vol. 14, No. 3, JuneJuly-August 2004, pp. 4.

[2] G. K. Singh, "Multi-Phase Induction Machine Drive Research - a Survey”, Electric Power Systems Res., Vol. 62, 2002, pp.139-147.

[3] R.Bojoi, F.Farina, M.Lazzari, F.Profumo, A. Tenconi, "Analysis of the Asymmetrical Operation of Dual three-Phase Induction Machines", Conf.Rec.IEEE-IEMDC'03, Madison (USA), June 2003, pp.429-435.

[4] R.Bojoi, F.Profumo, A.Tenconi, "Digital Synchronous Frame Current Regulation for Dual Three-Phase Induction Motor Drives", Conf.Rec.IEEE-PESC'03, Acapulco (Mexico), June 2003, 1475-1480.

[5] R. Bojoi, “Analysis, design and implementation of a dual three-phase vector controlled induction motor drive”, Doctoral thesis, 2002.

[6] R.Bojoi, M.Lazzari, F.Profumo, A. .Tenconi, "Digital Field Oriented Control for Dual ThreePhase Induction Motor Drives”, IEEE Transactions on Industry Applications, vol. 39, no. 3, may/june 2003.

[7] Y. Zhao and T.A. Lipo, "Space Vector PWM Control of Dual Three Phase Induction Machine Using Vector Space Decomposition”, IEEE Transactions on Industry Applications, Vol. 31, No. 5, September/October 1995, pp. 1100-1109.

[8] Paul C. Krause, “Analysis of electric machinery”, McGraw-Hill Book Company, Technology \& Industrial Arts, 1995.

[9] Semikron, "Power electronics systems SKS 21F B6U + E1CIF + B6CI 12 V12”, March 2006.

[10] Technosoft, "DSP Motion Starter Kits and Motion Control Kits User Manual”, Switzerland, February 2006. 